\title{
Ultrasonic and Viscous Behaviour of Hydroquinone in Alcohols
}

\author{
RAJ KUMAR ${ }^{1}$, Y.P. SINGH ${ }^{2}$ and S.S. YADAV \\ ${ }^{1}$ Deptt. of Chemistry, K.A. (PG) College, Kasganj-207123 (UP) India. \\ 2Deptt. of Chemistry, J.L.N. PG College, Bhopal-462002 (MP) India. \\ *Corresponding author E-mail: dr.rk.ksj@gmail.com \\ http://dx.doi.org/10.13005/ojc/330362
}

(Received: May 13, 2017; Accepted: May 30, 2017)

\begin{abstract}
The ultrasonic velocity $(\mathrm{V})$, density $(\rho)$ and viscosity $(\eta)$ measurements of Hydroquinone in n-propanol and iso-propanol have been carried out for the study of solute-solvent interaction. Experimental data have been used to calculate the isentropic compressibility $\left(\beta_{s}\right)$, intermolecular free length $\left(L_{f}\right)$, specific acoustic impedance $(Z)$, molar sound velocity $(R)$, relative association $\left(R_{A}\right)$ solvation number $\left(S_{n}\right)$ apparent molal adiabatic compressibility $\left(\phi_{k}\right)$, specific viscosity $\left(\eta_{\mathrm{sp}}\right)$, reduced viscosity $(\eta)$ and relative viscosity $\left(\eta_{\mathrm{r}}\right)$. The sign and magnitude of these properties have been used to interpret the experimental results in terms of solute-solvent interaction.
\end{abstract}

Keywords : Ultrasonic velocity, Density, Viscosity, Hydroquinone, $n$-propanol and iso-propanol.

\section{INTRODUCTION}

Knowledge of densities, viscosities and ultrasonic velocity of liquid mixture is important to understand the solute-solvent interactions between Hydroquinone in n-propanol and iso-propanol to develop new theoretical models and also for engineering application ${ }^{1-5}$. Hydroquinone, also benzene-1,4-diol or quinol was first obtained in 1820 by the French chemist Pelletier and Caventou ${ }^{6}$ via the dry distillation of quinic acid which obtained by the bark of cinchona trees. Hydroquinone is a skin-bleaching agent that is used to lighten the dark patches of skin caused by pregnancy, birth control pills, hormone medicine, or injury to the skin. Hydroquinone most common use is it ability to act as a reducing agent that is water soluble.

In view of growing interest, in this paper, the results of an ultrasonic velocity, density and viscosity to study the related acoustical parameters, for the binary systems of hydroquinone $+n$-propanol and hydroquinone + iso-propanol at $27^{\circ} \mathrm{C} \pm 0.05^{\circ} \mathrm{C}$ have been reported. The results are discussed in terms of solute-solvent interactions. 


\section{EXPERIMENTAL}

All the chemicals used in the present work were analytical reagent (AR) grade. The liquid mixtures of various concentration (mole/L) of hydroquinone + n-propanol and hydroquinone + isopropanol were prepared by mass in a $25 \mathrm{~cm}^{3}$ flask using a analytical balance. The speed of sound waves were obtained by using ultrasonic interferometer (Model F-81, Mittal Enterprises, New Delhi) at a fixed frequency of $2 \mathrm{Mhz}$ with an accuracy of $\pm 2 \mathrm{~ms}^{-1}$ and a constant temperature $27^{\circ} \mathrm{C} \pm 0.05^{\circ} \mathrm{C}$. An electronically digital operated constant temperature bath (RAAGA industries, Madras) has been used to circulate water through the double walled inter-ferometric cell made up of steel containing the experimental solution at the desired temperature. The density of pure solvents and solutions were determined using a specific gravity bottle of $10 \mathrm{ml}$. capacity. An Ostwald's viscometer which is $10 \mathrm{ml}$ capacity was used for the viscosity measurement. The viscometer was calibrated with fresh conductivity water immersed in the water bath which was kept at the experimental temperature. The time flow of water $\left(\mathrm{t}_{\mathrm{w}}\right)$ and the time flow of solution $\left(\mathrm{t}_{\mathrm{s}}\right)$ was measured with digital stop watch having an accuracy $\pm 3 \times 10^{-6} \mathrm{Nm}^{-2} \mathrm{~S}$. The temperature around the viscometer was maintained in an electronically controlled thermostatic water bath. The purity of chemicals was checked by comparing with their densities with literature values.

Using the measured data, some acoustical parameters have been calculated using the standard relations, Isentropic compressibility $\left(\beta_{s}\right)^{7}$ is given by

$$
\beta_{s}=1 / V^{2} \rho
$$

Intermolecular free length $\left(L_{f}\right)^{8}$ is calculated by

$$
L_{f}=K \cdot \sqrt{\beta_{s}}
$$
constant.

where $\mathrm{K}$ is the temp. dependent Jacobason calculated by

Specific acoustic impedance $(Z)^{9}$ is

$$
Z=V \cdot \rho
$$

Molar sound velocity $(R)$ is obtained by

$$
R=\bar{M} / \rho \cdot V^{1 / 3}
$$

$$
\& \quad \bar{M}=\frac{n_{1} m_{1}+n_{2} m_{2}}{n_{1}+n_{2}}
$$

where $n_{1}, n_{2}$ and $m_{1}, m_{2}$ are the number of moles and molecular weight of the solvent and solute respectively.

Relative association $\left(R_{A}\right)^{10}$ is given by

$$
R_{A}=\left(\rho / \rho_{0}\right) \cdot\left(V_{0} / V\right)^{1 / 3}
$$

where $V_{0}, V, \rho_{0}$ and $\rho$ are the ultrasonic velocity and density of the solvent and solution respectively.

Solvation number $\left(S_{n}\right)^{11}$ is calculated by

$$
S_{n}=n_{1} / n_{2}\left(\frac{1-\beta_{s}}{\beta_{s_{0}}}\right)
$$

Apparent molal adiabatic compressibility $\left(\phi_{K}\right)$ is given by-

$$
\phi_{K}=\frac{1000}{C, \rho_{0}}\left(\rho_{0} \beta_{s}-\beta_{s_{0}} \rho\right)+\frac{\beta_{s 0} \cdot M}{\rho_{0}}
$$

Where $\beta_{s o}, \beta_{s}, \rho_{0}, \rho$ are isentropic compressibility and density of solvent and solution respectively. $C$ is the concentration in mole/l. $M$ is the molecular weight of the solute. $\phi_{K}$ is the function of $C$ as obtained by Gocker from Debye-Huckel theory. ${ }^{12}$

Specific viscosity $\left(\eta_{\text {sp }}\right)$, Reduced viscosity $(\eta)$ and relative viscosity $\left(\eta_{r}\right)$ are calculated by the following well known relationship-

$\eta_{s p}=\frac{\eta-\eta_{0}}{\eta_{0}}$

$\eta=\frac{\eta_{s p}}{C}$

$$
\eta_{r}=\frac{\eta}{\eta_{0}}
$$


System : Hydroquinone + iso-propanol at $27^{\circ} \mathrm{C} \pm 0.05^{\circ} \mathrm{C}$

\begin{tabular}{|c|c|c|c|c|c|c|}
\hline $\begin{array}{l}\text { Conc. } \\
\text { (C) } \mathrm{mol} / / \mathrm{i} \text {. }\end{array}$ & 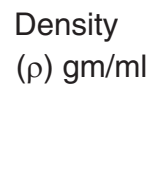 & $\begin{array}{l}\text { Ultrasonic } \\
\text { Velocity (V) }\end{array}$ & $\begin{array}{c}\text { Isentropic } \\
\text { Compressibility } \\
\left(\beta_{s}\right) \mathrm{Cm}^{2} / \text { dyne. } \\
10^{12}\end{array}$ & $\begin{array}{c}\text { Apparent molal } \\
\text { Adiabatic } \\
\text { Compressibility } \\
\left(\phi_{K}\right) \mathrm{cm}^{2} / \text { dyne } 10^{9}\end{array}$ & $\begin{array}{c}\text { Specific Acoustic } \\
\text { Impedance } \\
Z \times 10^{-5} \\
\text { (C.G.S.) }\end{array}$ & $\begin{array}{l}\text { Intermolecular } \\
\text { free length } \\
\left(L_{f}\right) \mathrm{A}^{\circ}\end{array}$ \\
\hline 0.0909 & 0.7905 & 1124.0 & 100.13 & -29.619 & 0.8885 & 0.6274 \\
\hline 0.1000 & 0.7915 & 1124.5 & 99.91 & -30.423 & 0.8900 & 0.6267 \\
\hline 0.1111 & 0.7927 & 1124.5 & 99.76 & -30.137 & 0.8913 & 0.6262 \\
\hline 0.1250 & 0.7942 & 1125.0 & 99.48 & -30.585 & 0.8934 & 0.6253 \\
\hline 0.1428 & 0.7962 & 1125.5 & 99.14 & -31.148 & 0.8961 & 0.6242 \\
\hline 0.1666 & 0.7988 & 1126.5 & 98.65 & -31.518 & 0.8998 & 0.6227 \\
\hline 0.2000 & 0.8025 & 1127.5 & 98.02 & -31.808 & 0.9048 & 0.6207 \\
\hline 0.2500 & 0.8080 & 1129.5 & 97.00 & -32.385 & 0.9126 & 0.6175 \\
\hline 0.3333 & 0.8171 & 1132.0 & 95.50 & -32.339 & 0.9249 & 0.6127 \\
\hline $\begin{array}{l}\text { Molar } \\
\text { Sound } \\
\text { Velocity(R) }\end{array}$ & $\begin{array}{l}\text { Solvation } \\
\text { Number } \\
\left(S_{n}\right)\left(R_{A}\right)\end{array}$ & 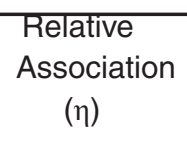 & $\begin{array}{c}\text { Viscosity } \\
\text { (Cantipoise) } \\
\eta\end{array}$ & $\begin{array}{r}\text { Specific } \\
\text { Viscosity } \\
\left(\eta_{\mathrm{sp}}\right)\end{array}$ & $\begin{array}{l}\text { Reduced } \\
\text { Viscosity } \\
\text { (ๆ)Centipoise }\end{array}$ & $\begin{array}{c}\text { Relative } \\
\text { Viscosity } \\
\left(\eta_{\mathrm{r}}\right)\end{array}$ \\
\hline 795.05 & 1.94 & 1.0127 & 2.1916 & 0.1714 & 1.8857 & 1.1714 \\
\hline 795.05 & 2.04 & 1.0139 & 2.2083 & 0.1803 & 1.8034 & 1.1803 \\
\hline 793.97 & 2.01 & 1.0154 & 2.2167 & 0.1848 & 1.6636 & 1.1848 \\
\hline 793.28 & 2.07 & 1.0172 & 2.2250 & 0.1892 & 1.5141 & 1.1892 \\
\hline 792.28 & 2.12 & 1.0196 & 2.2417 & 0.1981 & 1.3879 & 1.1981 \\
\hline 791.10 & 2.19 & 1.0226 & 2.2752 & 0.2160 & 1.2971 & 1.2160 \\
\hline 788.43 & 2.23 & 1.2071 & 2.3087 & 0.2340 & 1.1700 & 1.2340 \\
\hline 786.79 & 2.30 & 1.0335 & 2.3756 & 0.2697 & 1.0790 & 1.2697 \\
\hline 782.52 & 2.30 & 1.0443 & 2.4952 & 0.3144 & 1.0943 & 1.3144 \\
\hline
\end{tabular}

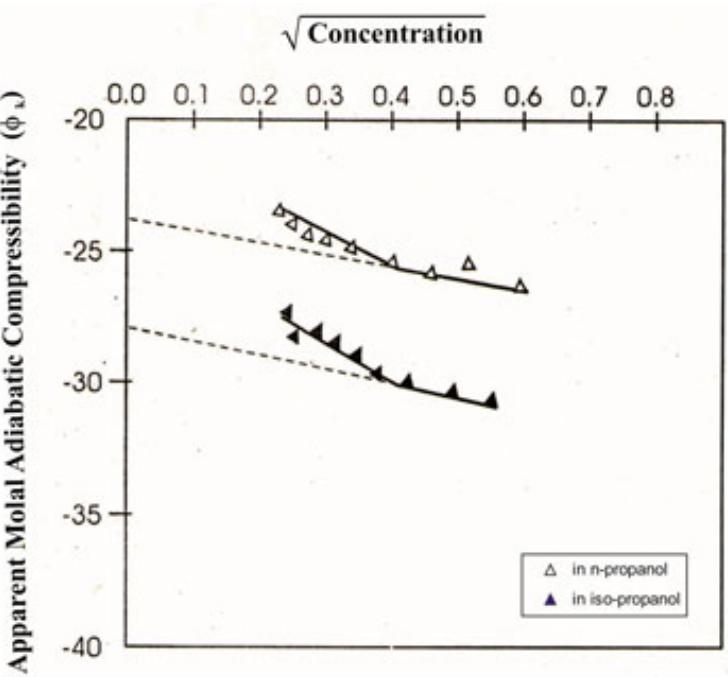

Fig. 1 : Apparent Model Adiabatic Compressibility Vs $\sqrt{\text { Concentration }}$ 
Where $\eta, \eta_{0} \& C$ are the viscosity of solution, solvent and concentration of solution in mole/L respectively.

\section{RESULTS AND DISCUSSION}

Ultrasonic velocity $(V)$ in the solution of hydroquinone in n-propanol and iso-propanol increases with increasing concentration of hydroquinone. The variation of velocity with concentration $(C)$ of hydroquinone solution in n-propanol and iso-propanol can be expressed by the following relation-

$$
\frac{d v}{d c}=-\frac{V}{2}\left[\frac{1}{\rho}\left(\frac{d \rho}{d c}\right)+\frac{1}{\beta_{s}}\left(\frac{d \beta_{s}}{d c}\right)\right]
$$

The result shows that while the density increases, the isentropic compressibility decreasing with increasing concentration of solute ${ }^{13}$ and the quantity $(d \rho / d c)$ is positive while $\left(d \beta_{s} / d c\right)$ is negative. Since the value of $\left[1 / \beta_{s}\left(d \beta_{s} / d c\right)\right]$ are greater than the values of $[1 / \rho(d \rho / d c)]$ for hydroquinone solution in n-propanol and iso-propanol. The concentration derivative of velocity $(d v / d c)$ is positive ${ }^{14-16}$ i.e. the ultrasonic velocity increases with increasing the concentration of hydroquinone in solution.

The isentropic compressibility $\left(\beta_{s}\right)$ of hydroquinone solutions decreases with increase in the molar concentration of solute. The results of isentropic compressibility have been explained in terms of Bechem's equation. ${ }^{17}$

System : Hydroquinone $+\mathrm{n}$-propanol at $27^{\circ} \mathrm{C} \pm 0.05^{\circ} \mathrm{C}$

$\begin{array}{lll}\text { Concentration } & \text { Densityl } & \text { Ultrasonic) } \\ \text { (C) } \mathrm{mol} / \mathrm{li} . & (\rho) \mathrm{gm} / \mathrm{m} & \text { Velocity (V }\end{array}$

Isentropic Apparent molal Specific Intermolecular Compressibility Adiabatic Acoustic free length $(L f) A^{\circ}$ $\left(\beta_{\mathrm{s}}\right) \mathrm{Cm} 2 /$ dyne. Compressibility Impedance $10^{12} \quad(\phi K) \mathrm{cm} 2 /$ dyne $\quad(C . G . S$. $10^{9} \quad \mathrm{Z} \times 10^{-5}$

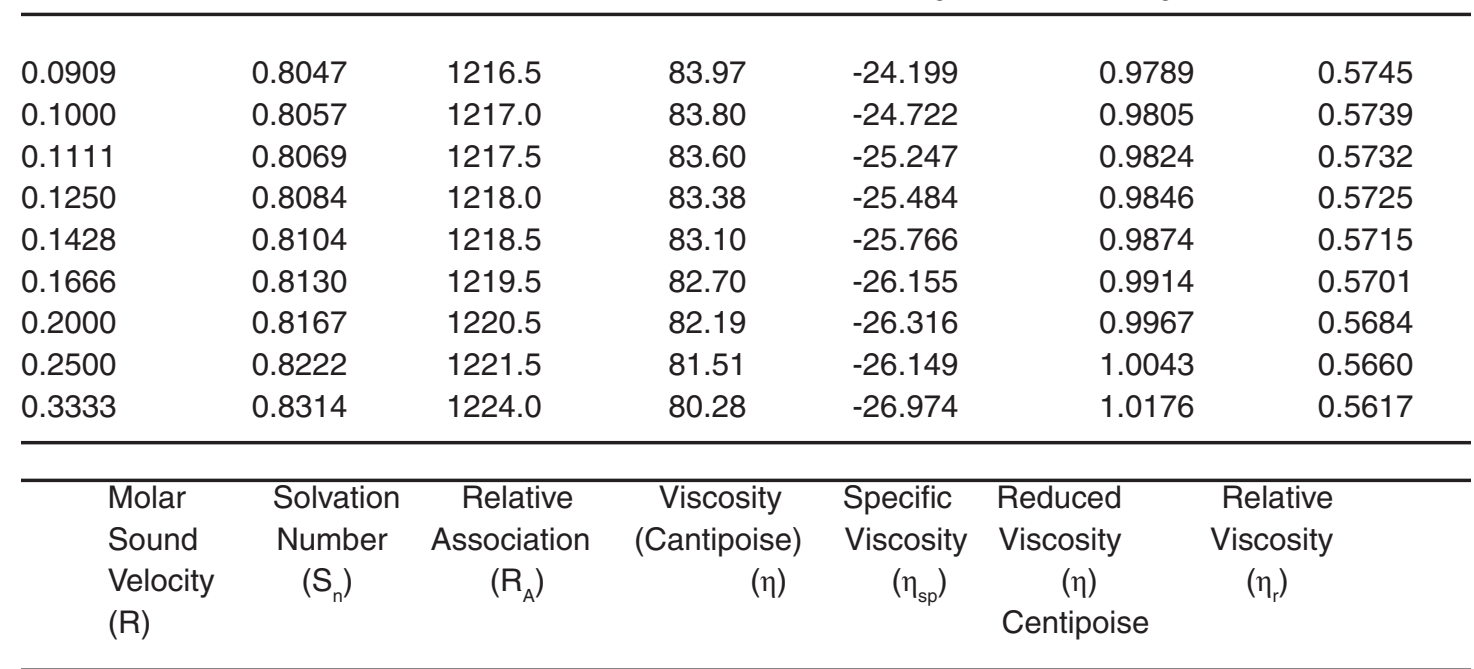

\begin{tabular}{rrrrrrr}
\hline 801.87 & 1.93 & 1.0123 & 1.9686 & 0.0232 & 0.261 & 1.0232 \\
801.42 & 2.01 & 1.0134 & 1.9837 & 0.0311 & 0.3113 & 1.0311 \\
800.87 & 2.09 & 1.0147 & 1.9913 & 0.0350 & 0.3158 & 1.0350 \\
800.16 & 2.13 & 1.0167 & 1.9989 & 0.0390 & 0.3122 & 1.0390 \\
799.15 & 2.17 & 1.0190 & 2.0140 & 0.0469 & 0.3283 & 1.0468 \\
798.14 & 2.23 & 1.0220 & 2.0443 & 0.0626 & 0.3759 & 1.0626 \\
798.34 & 2.26 & 1.0263 & 2.0746 & 0.0783 & 0.3919 & 1.0783 \\
763.61 & 2.23 & 1.0330 & 2.1742 & 0.1098 & 0.4395 & 1.1098 \\
789.24 & 2.24 & 1.0438 & 2.2109 & 0.1492 & 0.4477 & 1.1492 \\
\hline
\end{tabular}




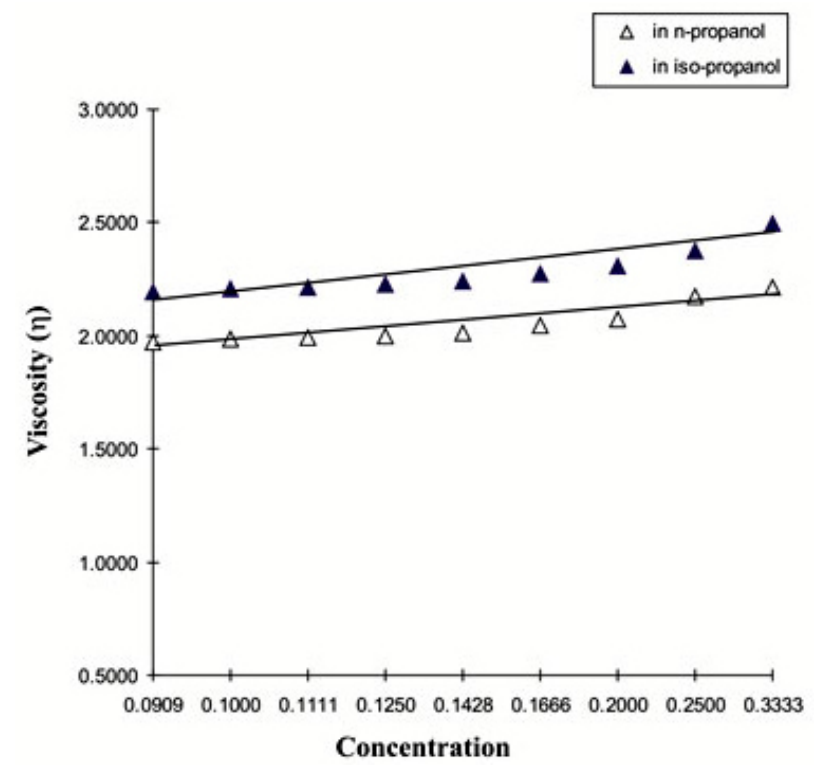

Fig. 2 : Viscosity Vs Concentration

$$
\beta_{s}=\beta_{s_{0}}+A C+B C^{3 / 2}
$$

where $\beta_{s o}$ is the isentropic compressibility of the solvent, $C$ is the molar concentration and $A \& B$ are constant $[A(-14.50$ and -15.60$)$ and $\mathrm{B}(6.868$ and 1.389)].

The value of constants $(A \& B)$ were obtained from the intercept and slope of plots $\left[\left(\beta_{s}-\beta_{s 0}\right) / C\right]$ Vs $\sqrt{C}$. The complementary use of isentropic compressibility data can provide interesting information about solute-solvent interaction. Apparent molar adiabatic compressibility $\left(\phi_{K}\right)$ varies linearly as the square root of concentration $(\sqrt{C})$. The values of apparent molal adiabatic compressbilities are negative with the increase in molar concentration of hydroquinone in n-propanol and iso propanol. ${ }^{18}$ The values of $\phi_{\mathrm{K}}\left[-24.30\right.$ and $-28.10 \mathrm{~cm}^{2} /$ dyne. $\left.10^{\circ}\right]$ for the solution of hydroquinone in $n$-propanol and iso- propanol respectively. The values of $\phi_{\mathrm{K}}$ were evaluated by extra plotting. The graph of $\phi_{\mathrm{K}} \mathrm{Vs} \sqrt{C}$ (shown in fig 1).

The intermolecular free length $\left(L_{f}\right)$ decreases while the specific acoustic impedance $(Z)$ increases with an increase in the concentration of hydroquinone in solutions which can be explained on the basis of lyophobic interaction between solute and solvent molecules which increase the intermolecular distance making relatively under gaps between the molecules and becoming the main cause of impedance in the propagation of ultrasound waves. These results are in agreement with results reported by Bhandakkar ${ }^{19}$ for methyl methacrylate with methanol, $p$-dioxane and cyclohexane. The molar sound velocity $(R)$ has been found to varied linearly with the molar concentration of hydroquinone in solutions. Linear decrease of molar sound velocity with molar concentration has been also reported for cerous nitrate salt by Singh ${ }^{20}$. The relative association $\left(R_{A}\right)$ and solvation number $\left(S_{n}\right)$ increases with molar concentration has been also reported by Diwidi et. $a^{21}$ in complex formation between $\mathrm{KCl}$, $\mathrm{CaCl}_{2}$ and $\mathrm{HgCl}_{2}$.

The increase in viscosity may be due to the increasing tendency of hydroquinone molecules to form aggregates with the increase in the hydroquinone concentration in solution. The plots of viscosity Vs molar concentration are shown in figure 2. The slops of lines is found to be positive in each case. Linear increase of the viscosity results has been also reported for some ternary electrolytes in dioxane water mixture by $\mathrm{Das}^{22}$. These results of viscosity indicates that there is a significant interaction between the solute and solvent molecules. ${ }^{23-25}$ 


\section{CONCLUSION}

The solute-solvent interaction present in hydroquinone with n-propanol \& iso-propanol have been studied by ultrasonic velocity, density and viscosity study. On the basis of the results obtained from the study, it is concluded that the solutesolvent interaction in the solution of hydroquinone with n-propanol and iso-propanol is significant and the computed acoustical parameters and their values indicates to the presence of solute-solvent interaction in the solutions.

\section{REFERENCES}

1. Arrozo, S., Nerin, C. and Benito, Y. : Ultraonics sonochemistry, 2007, 14343.

2. Dabid, R., Villermous, J. : Chemical engineering science: 1991., 46(4), , 1129.

3. Prabhakar, S. \& Gopal, R. : Ind. J. Pure and Appl. Phys., 2008.,46, 251.

4. Thirumaran, S., Suguna, M. and Salvi, S.R., Research J. Chemi., Enviran.,2009, 13(3), 81.

5. F.J. Millero, A. Surdo and Shine, J. Phys. Chem., 1978. 82, 784

6. Pelletier \& Caventou (1820), Annales de chimie et de physique, $2^{\text {nd }}$ Series, $15: 289$ 318, 337-364.

7. D.O. Mason, Philos. Mag., 1929. 8, 218

8. B. Jacobason, Acta Chem. Scand., 1952. 6, 1485

9. I.E. Elpiner, Ultrasound Physcal, Chemical and Biological effects, New York, consultants Bureau, 1960. 371

10. A. Wdeissler, J. Chem. Phys., 1947.15, 210

11. A.Passynskii, Act. Physicco. Chem., (U.R.S.S.) 8, 1933, 357; J. Phys. Chem. (U.S.S.R.), 11, 1938, 451.

12. Debye and Huckel, Physik Z., 1923.24, 185

13. Riyazuddin and Imran Khan, J.Thermodynamic
Acta, 2009. 483, 45,

14. S. Prakash, and C.V. Chaturvedi, Ind. J. Chem., 1972., 10, 669.

15. K. Rambrahman and M. Suryanarayan, Ind. J. Pure \& Appl. Phys., 1968. 6, 422

16. I.F. Mikanailor, M.V. Rozina and V.A. Snutilavakut, Zh., 1964.,. 10, 213

17. Bachem, C., Physica (Nrtherlands) 1935. 101, 218

18. T. Sumathi and M. Varalakshmi, Rasayan J. Chem., 2010. 3, 550-558

19. V.P. Bhandakkar, IOSR J. of Appl. Physics, 2012. $1,38 \& 43$

20. S.Singh, Ph.D. Thesis, University of Allahabad 1978.

21. K.S. Dwidi, Om Prakash and S. Prakash, Vijana Parishad Anusandhan Patrika, 1978. . 21, . 3, 225-236

22. R.B. Das, Ind. J. Chem,1977.., 15A, 1098

23. R.H. Stokes and R. Mills, "Viscosity of electrolytes and related Properties" (Pergmen Press, New York) 1965

24. J.E. Desnoyers and G. Perron, J. Soln. Chem.,1972 1, 199.

25. Mohd. Yaser, I. Journal of Pure \& Appl. Physics, 2013.I. 51, 621-626 